\title{
Copy number variation associated with Kallmann syndrome: new genetics insights from genome-wide studies
}

\author{
Ericka B Trarbach
}

Asian Journal of Andrology (2011) 13, 203-204; doi:10.1038/aja.2010.115; published online 8 November 2010

Kallmann syndrome and normosmic isolated hypogonadotropic hypogonadism ( $\mathrm{IHH})$ are developmental disorders characterized by hypogonadotropic hypogonadism that, in the former case, is coupled to loss of the sense of smell. ${ }^{1}$ Linkage analyses, deletion mapping and candidate gene approaches uncovered several loci in the pathogenetic mechanism of these diseases (Figure 1). ${ }^{2,3}$ However, loss-of-function mutations in these genes account for only $30 \%$ of hypogonadotropic hypogonadism cases, suggesting that many disease-causing genes remain to be discovered. $^{2-4}$ Copy number variations (CNVs) include inherited, de novo and somatically acquired deviations from a diploid state (deletions, duplications, insertions and com- plex genomic rearrangements) within a particular chromosomal segment. They usually are $1 \mathrm{~kb}$ in length or larger. ${ }^{5}$ Since the discovery of the important role of CNVs in human genome variability and also the recent development of high-resolution microarraybased technologies, a number of studies using these variants as genetic markers have emerged. Hence, CNVs are considered high risk factors for a considerable fraction of inherited and acquired diseases. ${ }^{5-7}$

In Asian Journal of Andrology, a recent report by Zhang et al. ${ }^{8}$ provided some evidence for the potential involvement of CNVs in Kallmann syndrome. The authors used the array technology to investigate the genomewide profile of structural variations in one consanguineous family with Kallmann syndrome. ${ }^{8}$ The results revealed that affected individuals had common CNVs (microdeletions) on five distinct chromosomal regions: 1p21.1, 2q32.2, 8q21.13, 14q21.2 and Xp22.31. Interestingly, the variant on $\mathrm{Xp} 22.31$ was found in an intronic region of KAL1, a gene responsible for X-linked form of Kallmann syndrome. Molecular testing for KAL1 (and also for FGFR1) was found to be normal, ${ }^{8}$ although alterations outside the exonic and splice site junction regions typically studied could not be excluded. In addition, genomic microdeletion in this Xp22.3 CNV was found in one of 29 Han Chinese sporadic Kallmann syndrome patients and in one of four other familial

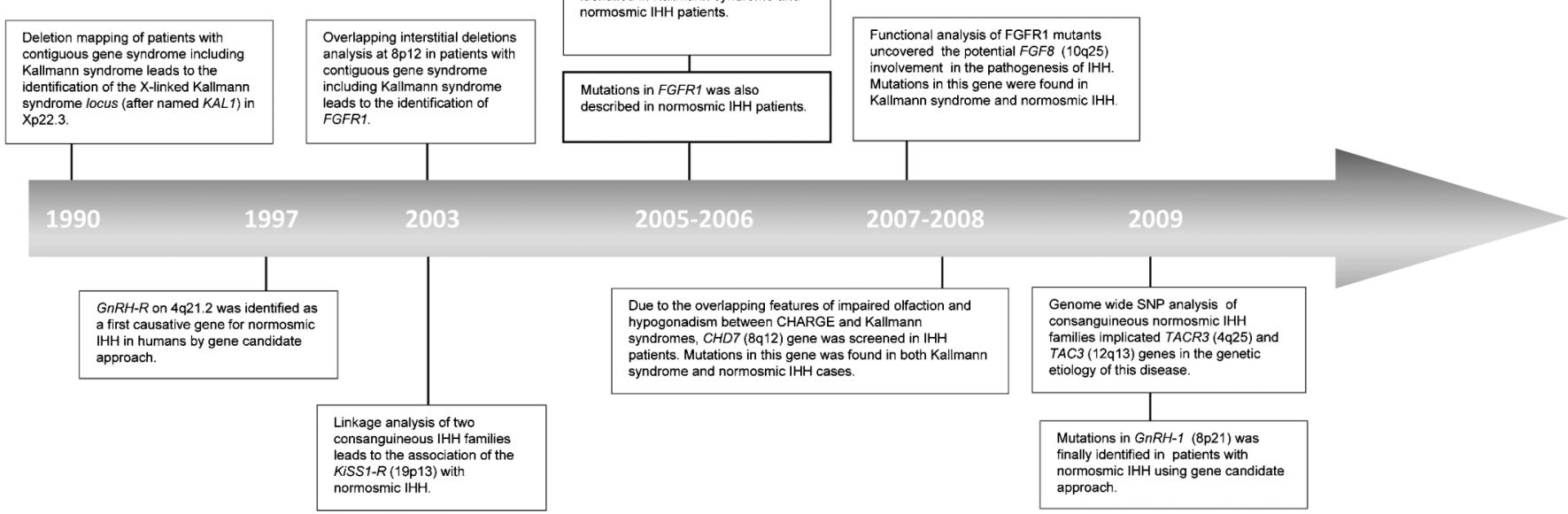

Figure 1 Goals in the genetic etiology establishment of human hypogonadotropic hypogonadism: Kallmann syndrome and normosmic IHH. IHH, isolated hypogonadotropic hypogonadism.

Unity of Endocrinology_LIM25 and LIM42, Faculty of Medicine, University of Sao Paulo, 01246-903 Sao Paulo, Brazi

Correspondence: Dr E B Trarbach (trarbach@hotmail.com) 
cases, but not in 26 Han Chinese sporadic normosmic $\mathrm{IHH}^{8}$

Although the work of Zhang et al. ${ }^{8}$ was based in a very limited number of family members, the rare variants found only among the affected individuals account for a step further towards the better understanding of hypogonadotropic hypogonadism pathophysiology. For example, do the CNVs in the intronic region of KAL1 have any impact on these gene activities? Because CNVs are increasingly implicated in numerous diseases through a variety of mechanisms, ${ }^{5}$ it is possible that an intronic microdeletion disrupts control elements of splicing, leading to gene loss-of-function. Even though the intronic CNV in KAL1 gene variant was not found neither in healthy family members nor in a control population suggesting that possibly it is phenotypically unfavorable, the pathological relevance of this variant will merit further investigations.

The paper also highlights the importance of CNVs in genome-wide projects to eventually help researchers to locate promising candidate genes for complex diseases. For instance, systematic exploration of CNVs in association studies have found susceptibility to HIV-1, lupus and Crohn's disease involving CNVs in CCL3L1, FCGR3B and C4, and DEFB4 genes, respectively (reviewed in Refs 5 and 7). Zhang et al. ${ }^{8}$ have also identified four autosomal CNVs that could be associated with Kallmann syndrome. However, we cannot exclude that these results represent false-positive findings; thus, replication is needed before one can conclude that these genomic regions contain genes that modulate human IHH. Accordingly, extensive genomic scanning for variations in new series of Kallmann syndrome and normosmic IHH could provide additional support for the results of Zhang et al. ${ }^{8}$ or underline other interesting regions related to IHH. It is undeniable that information provided by such studies is critical to improve our knowledge in the molecular basis of $\mathrm{IHH}$ and should be encouraged in years to come. The major challenge will be accurate interpreta- tion of how genomic imbalances could be pathogenic in this disease.

1 Layman LC. Hypogonadotropic hypogonadism. Endocrinol Metab Clin North Am 2007; 36: 283-96.

2 Silveira LF, Trarbach EB, Latronico AC. Genetics basis for $\mathrm{GnRH}$-dependent pubertal disorders in humans. Mol Cell Endocrinol 2010; 324: 30-8.

3 Tsai PS, Gill JC. Mechanisms of disease: insights into Xlinked and autosomal-dominant Kallmann syndrome. Nat Clin Pract Endocrinol Metab 2006; 2: 160-295.

4 Hardelin JP, Dodé C. The complex genetics of Kallmann syndrome: KAL1, FGFR1, FGF8, PROKR2, PROK2, et al. Sex Dev 2008; 2: 181-93.

5 Beckmann JS, Estivill X, Antonarakis SE. Copy number variants and genetic traits: closer to the resolution of phenotypic to genotypic variability. Nat Rev Genet 2007; 8: 639-46.

6 Cooper GM, Zerr T, Kidd JM, Eichler EE, Nickerson DA. Systematic assessment of copy number variant detection via genome-wide SNP genotyping. Nat Genet 2008; 40: 1199-203.

7 Lee C, Scherer SW. The clinical context of copy number variation in the human genome. Expert Rev Mol Med 2010; 12: e8.

8 Zhang S, Tang Y, Wang T, Yang J, Rao K et al. Clinical assessment and genomic landscape of a consanguineous family with three Kallmann syndrome descendants. Asian J Androl 2010; published online 1 Nov 2010. 